\title{
Heating and Cooling of an Aluminium-Cased Parallel Flow Microreactor for Steam-Methane Reforming
}

\author{
RAIS Hanizam Madon ${ }^{a}$, MUHAMMAD Afiq M. Zamree, \\ SHAHRIN Hisham Amirnordin, MAS Fawzi ${ }^{{ }^{*}}$ \\ Energy Technologies Research Group (EnRG), Center for Energy and Industrial Environment \\ Studies (CEIES), Universiti Tun Hussein Onn Malaysia, 86400 Parit Raja, Batu Pahat, Johor, \\ Malaysia. \\ araismadon@uthm.edu.my, bfawzi@uthm.edu.my
}

Keywords: Microreactor, temperature, outlet stream

\begin{abstract}
A prototype aluminium microreactor for steam methane reforming process to produce hydrogen syngas, with parallel flow microchannels was developed. The microreactor was heated up to $400^{\circ} \mathrm{C}$ using a Bunsen burner at distance of $10 \mathrm{~mm}$ below it surface. Whereby two condition of burner open flow which are $1 / 3$ and $2 / 3$ took place in order to investigate its heating effect on outlet stream temperature. From the results, show that both Bunsen burner flow slightly show the same tendency of increasing and decreasing state, which indicated the optimum point of heat transfer to the systems for a cycle. But, the 2/3 opening Bunsen burner flow give the reliable contact reaction time at minimum operating condition of $400{ }^{\circ} \mathrm{C}$ and 1 bar compare to $1 / 3$ opening. This is due to its ability for lays above the set temperature point with longest duration time. From this results can conclude that, the relationship between contact flame area and microreactor surface on outlet flow temperature had been developed. The outlet stream temperature is proportional to the Bunsen burner opening, based on biggest area of flame contact yield the highest optimum temperature point with longest reaction time.
\end{abstract}

\section{Introduction}

The world is facing a reduction of fuel crisis in search of clean, abundant alternative fuel. Other than optimizing fossil fuel such as diesel and petrol, researchers also have conducted extensive studies of others potential alternative fuel including hydrogen. The automotive industries have been introduced to the engine technology that used a hydrogen fuel system to replace fossil fuel. Currently, almost $96 \%$ of the world's hydrogen demand is supplied by traditional fossil fuels, and about half of it, is comes from natural gas which the main composition is methane. The production of hydrogen from various hydrocarbons especially methane mainly comes from the chemical reaction process of catalytic reforming technologies which consist such as steam reforming, partial oxidation, and auto thermal reforming. Among these, catalytic methane steam reforming has the advantage of relatively low reaction temperature and high hydrogen content in the reforming products, and it is currently regarded as the most cost effective and highly developed type of reforming for hydrogen production[1-3]. Steam reforming of natural gas on fixed nickel catalyst packed bed reactor is the most economical process of producing hydrogen in areas of large amount natural gas sources. On the other hand, steam methane reforming on nickel in microreactor poses new opportunities to be explored $[2,3]$.

The microreactor offers many advantages such as improvement in energy efficiency, reaction speed, reliability, scalability, better control and possibly better yield and selectivity compared to those of conventional reactor. The use of microreactor in steam reforming potentially minimizes the temperature gradient, and ensures higher average temperature and process efficiency. It is usually made of aluminum sheets, steel, ceramics and glass, where by inside of it is attached a flow structures called microchannel that act as a liquid flow channel to react steam-methane with catalyst [3-6]. 
The steam methane reforming is an endothermic process with elevated temperature of $400^{\circ} \mathrm{C}$ $900{ }^{\circ} \mathrm{C}$ and 1-30barg pressure applied, therefore make it become an expensive process. The specified catalyst nickel or noble base (as rhodium, palladium) must be installed inside these microchannel. This microreactor also needs to stand a high amount of heat from the burner to extract the heat energy and transfer it to the microchannel. The heat was distributed to the catalyst ensuring the thermal cracking take place during steam mixing up with methane gas. In order to produce a reaction at desired operating temperature, the heating and cooling process took place onto the microreactor $[2,3,6,7]$.

This project intends to investigate the heating and cooling characteristics of the microreactor for the steam-methane reforming in order to secure the set operating temperature from raising or fallen below point. The next section describes the experimental set up of the microreactor testing apparatus, running method, and results is discuss in detail before being concluded on the last section of this paper.

\section{Methodology}

A Bunsen burner was placed at $10 \mathrm{~mm}$ from the bottom of microreactor whereby two thermocouples were installed at the pipe fitting outlet and top surface of microreactor. A diagram of this experiment setup is shown in Fig. 1 which consist of steam - methane supply, microreactor and process instrumentation. The temperature and pressure was set at $400^{\circ} \mathrm{C}$ and 1 bar. The thermocouple was connected to the data logger for temperature against the time analyse. Bunsen burner flame was set at two conditions which are $1 / 3$ and $2 / 3$ opening due to its full opening were 3 turns. Microreactor was heated with the Bunsen burner to increase and reduces the temperature test for two condition which are without and with steam-methane flow for both Bunsen burner opening flow. The mixture ratio between steam to methane was $1: 1$. Functionally the thermal logger recorded the maximum temperature that microreactor can withstand.

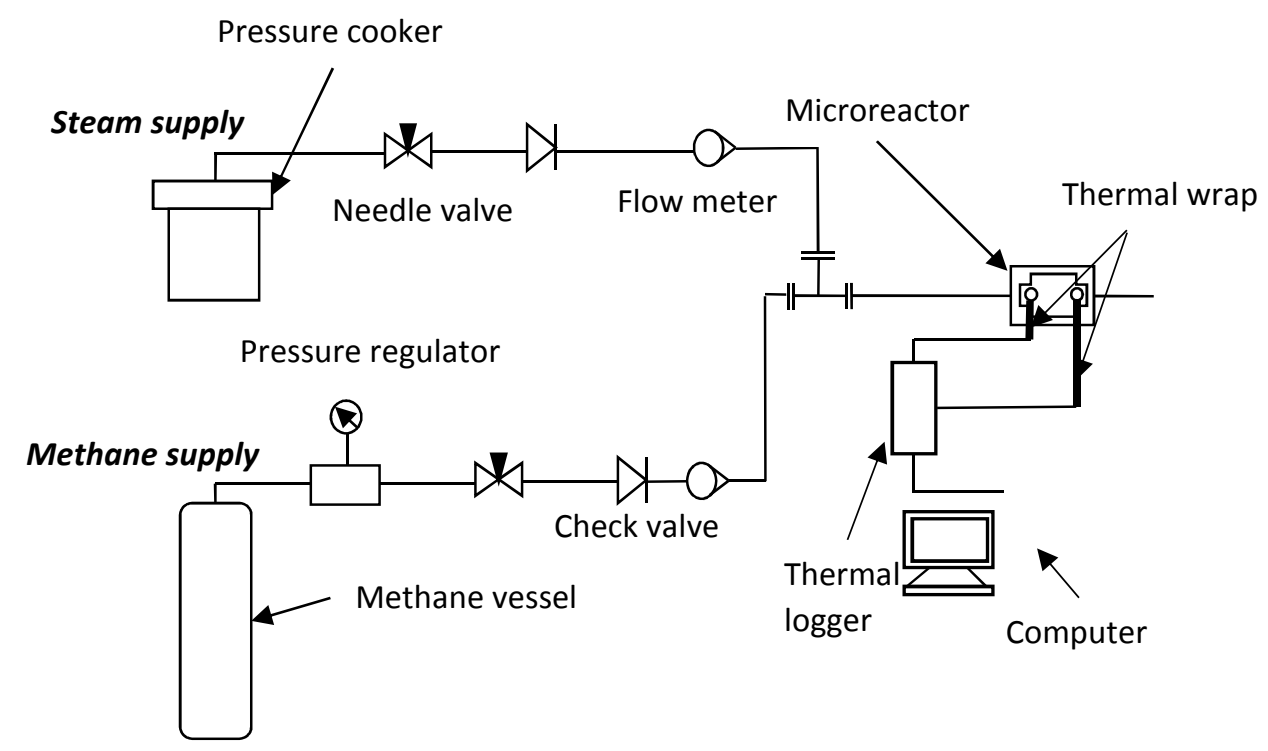

Fig. 1: Experiment setup for microreactor test

Aluminium was selected as a based material for the microreactor and consist of microchannel with sizing of $0.75 \mathrm{~mm}$ depth and $0.5 \mathrm{~mm}$ width as shown in Fig 2 . Hence there are also 2 holes for the inlet and outlet steam-methane flow. 


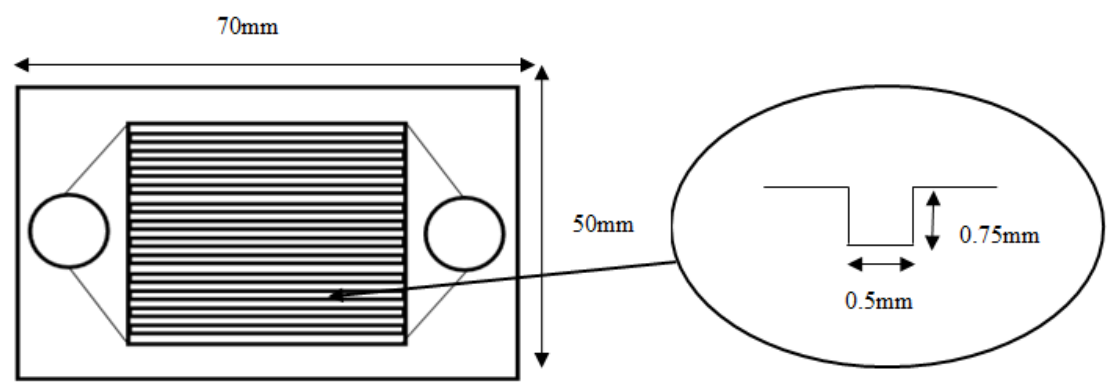

Fig. 2: The area of microchannel inside the microreactor

\section{Result and Discussion}

\section{Ilustration of flame contact area to the microreactor surface}

From the Fig 3 show the illustration flame diameter for the $1 / 3$ and $2 / 3$ opening bunsen burner flow at the top view direction. The diameter of the $1 / 3$ was $50 \mathrm{~mm}$ followed by $65 \mathrm{~mm}$ for $2 / 3$ Bunsen burner flow. Meanwhile the Fig 4 shows the flame side view for both $1 / 3$ and 2/3 Bunsen burner flow which represent flame contact surface.

The flame contact surface area is proportional to the Bunsen burner opening condition. Therefore heat suppy to the microreactor is more wide and equivalent ratio of flame area to the microreactor surface is large. The $2 / 3$ opening yield $200 \%$ contact area compare to $1 / 3$, straightly make it as the better option for heat transfer rate.

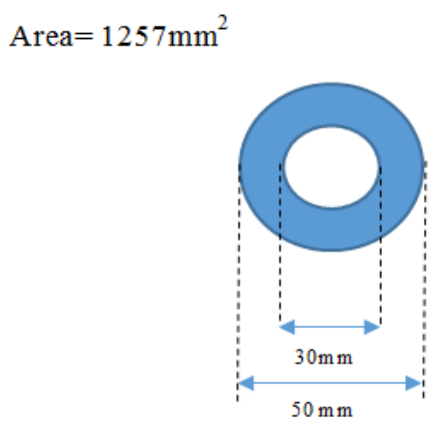

(a)

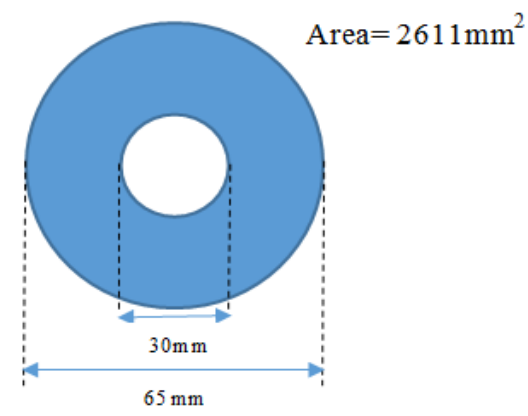

(b)

Fig. 3: Flame top views a) 1/3 Bunsen burner flow, b) 2/3 Bunsen burner flow

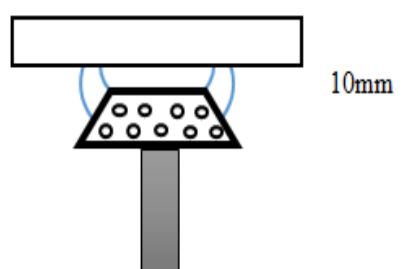

(a)

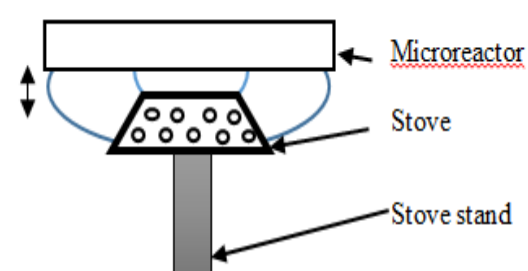

(b)

Fig. 4: Flame side view a) 1/3 Bunsen burner flow, b) 2/3 Bunsen burner flow 


\section{Effect on outlet stream temperature without steam-methane flow}

From the Fig 5 had showed that relation between the heat contact area and microreactor surface on outlet flow temperature for without steam-methane. Both Bunsen burner flow slightly show the same tendency of increasing and decreasing state. This indicates the optimum point of heat transfer to the systems for a cycle. The 1/3 opening Bunsen burner flow show the lowest temperature point per heating time compare to $2 / 3$ opening, therefore contact time for reaction process is lesser for the minimum operating temperature of $400^{\circ} \mathrm{C}$. Hence the $2 / 3$ opening gives reliable reaction contact time, base on biggest flame area yield highest temperature point per time with extra 400 seconds reaction time compare to the $1 / 3$ opening.

\section{Effect on outlet stream temperature with steam-methane flow}

As show in Fig 6, relation of the heat contact area to the microreactor surface on outlet flow temperature for steam-methane flow through microreactor. More over for the both Bunsen burner flow slightly lays on minimum reaction temperature border, eventhough their got the same patern of increasing and decreasing state to define the optimum point of heat transfer. The $2 / 3$ opening show longest contact reaction time, but it's still got potential of temperature drop below $400^{\circ} \mathrm{C}$. These unstable temperatures create the coking problem matter of formation carbon and straighly lead to the decrease of hydrogen yield and methane conversion.

The existence of temperature different for the outlet condition of with and without steammethane flow, had given big impact for the heat transfer rate. For the outlet with steam-methane flow measure the lowest temperature due to its fluids properties inside the systems. Methane is cooler than the temperature of the steam for operating condition at 1 bar. If both fluids were mixed, whereby the methane temperature lays on $-160{ }^{\circ} \mathrm{C}$ till $-140^{\circ} \mathrm{C}$ and steam range of $120{ }^{\circ} \mathrm{C}$ till $130{ }^{\circ} \mathrm{C}$ only, lead to the large gap difference and produce an unstable temperature effect. Compare to the without steam-methane flow, heat transfer rate was done on single air fluids only, therefore the heat transfer coefficient is much better than mixed different temperature fluids.

\section{Temperature correlation between flame contact areas with outlet stream}

The outlet stream temperature is proportionally to the flame contact areas on microreactor surface. These results clearly shown that the largest area give highest heat transfer to the microreactor output and maximum yields of temperature been achieved. From this outcome, researcher can predict the optimum point of heat transfer per cycle, whereby heating and cooling process system is installed in order to secure the desired operating condition and straightly avoid prone of carbon formation instead of hydrogen yields. Based on Fig 6, which is the actual condition for steam methane reforming, the heating and cooling will be pinch at the reaction time of 1000 seconds.

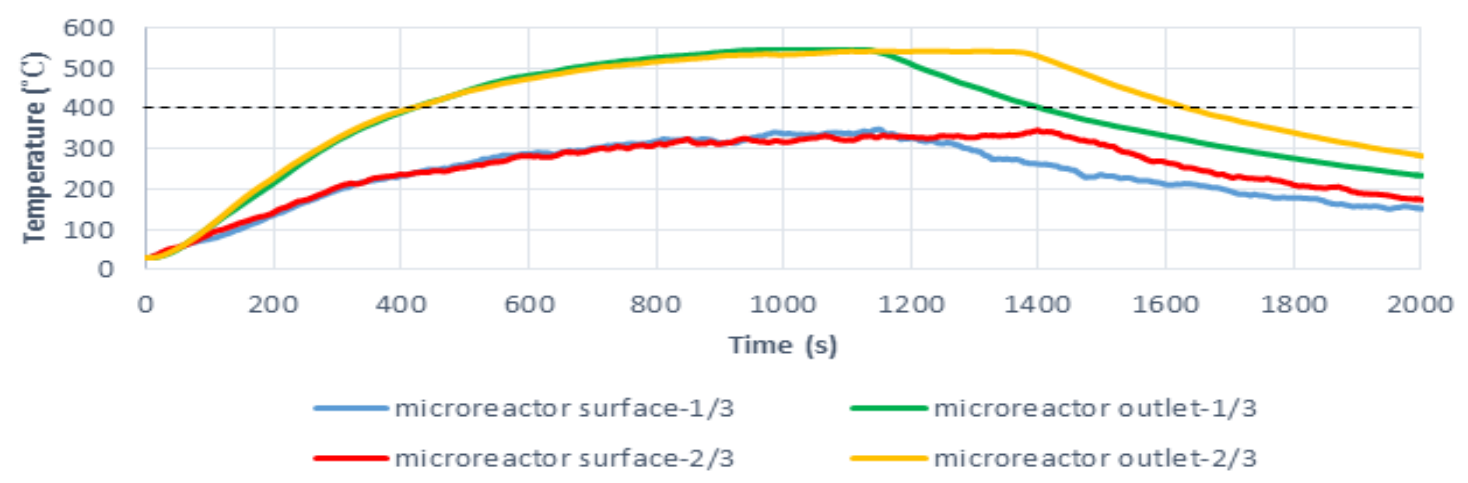

Fig. 5: Temperature $\left({ }^{\circ} \mathrm{C}\right.$ ) against time (s) $1 / 3$ and $2 / 3$ flame flow of Bunsen burner without steam-methane flow 


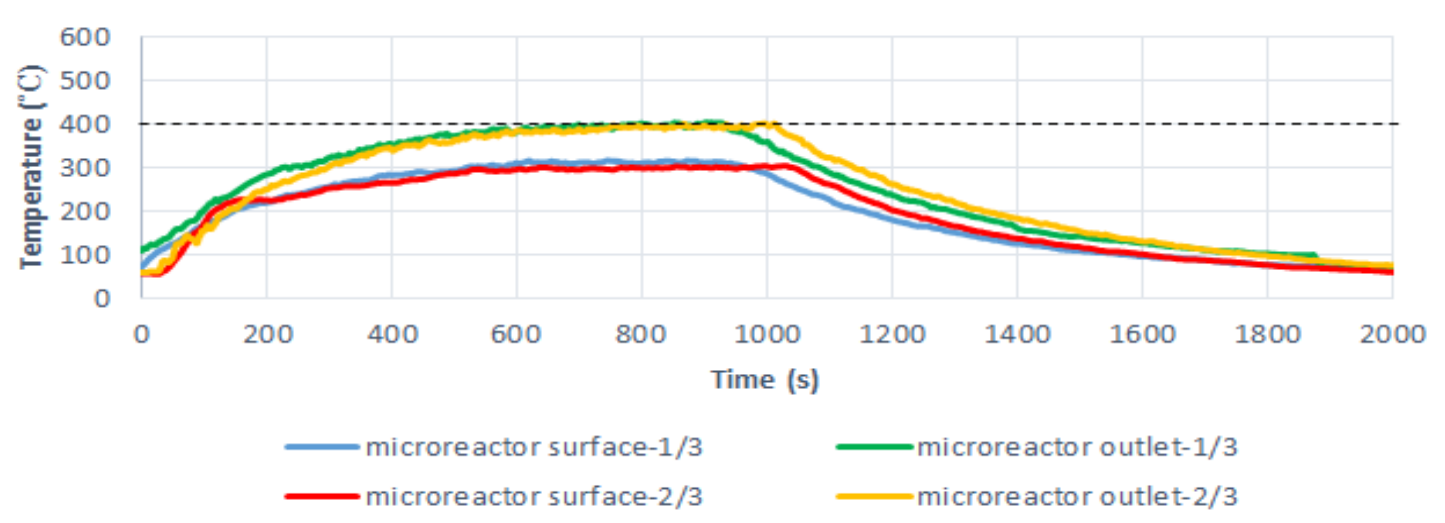

Fig. 6: Temperature $\left({ }^{\circ} \mathrm{C}\right.$ ) against time (s) $1 / 3$ and 2/3 flame flow of Bunsen burner with steam -methane flow

\section{Conclusion}

In this paper, the relation between contact flame area and microreactor surface on outlet flow temperature had been defined for the steam methane reforming process. The properties of fluids flow inside the systems also play major role to determine the heat transfer coefficient. These current condition of $2 / 3$ opening burner Bunsen flow give the most reliable contact reaction time based on minimum reaction temperature. Hence the optimum heat transfer per cycle is described as point of installation heating and cooling process system. Therefore, for the temperature different problem in steam-methane flow, a projection upwards of heat transfer need to be done in order to secure its lays above the minimum reaction condition.

\section{Acknowledgement}

The authors would like to thank the Ministry of Education Malaysia for partly supporting this research under the Fundamental Research Grant Scheme (FRGS) vot 1421.

\section{References}

[1] Heinzel A, Vogel B, Hiugner P., Reforming of natural gas hydrogen generation for small scale stationary fuel cell systems. J. Power Sources, 105 (2002) 202-207.

[2] Wang F., Qi B., Wang G., Li L.. Methane steam reforming: Kinetics and modeling over coating catalyst in micro-channel reactor. International J. Hydrogen Energy. 38 (2013) 5693-5704.

[3] Barnali B., Narayan C.P., Swati N..2013.Production of hydrogen by steam reforming of methane over alumina supported nano-NiO/SiO2 catalyst. Cat. Today . 207 (2013) 28- 35.

[4] Chunshe, C., Yong, W., Robert, T.R.. Heterogeneous reactor model for steam reforming of methane in a microchannel reactor with microstructured catalysts. Cat. Today, 110 (2005) 9297.

[5] Kolb, G., Schurer, J., Tiemann, D., Wichert, M., Zapf, R., Hessel, V., Lowe, H. Fuel processing in integrated micro-structured heat-exchanger reactors, J. Power Sources, 171 (2007) 198-204.

[6] Ayabe. Catalytic autothermal reforming of Methane and propane over supported metal catalys, Applied Catalysis A: General, 241(2003) 261-269.

[7] Palm, C., Cremer, P., Peters, R., Stolten, D. Small-scale testing of a precious metal catalyst in the autothermal reforming of various hydrocarbon feeds, J. Power Sources, 106 (2002) 231 237. 